\title{
Impacts of School Climate on Preschool Teachers' Attitudes towards Inclusion of Students with Special Needs in China
}

\author{
Chao Sun \\ Shanghai Normal University Tianhua College \\ Shanghai, China
}

\begin{abstract}
The purpose of the study was to describe the relationship between teachers' perceptions of school climate and their attitudes towards inclusion. An online survey was completed by 816 preschool teachers in Shanghai, China who responded to items regarding their demographic characteristics, perceptions of school climate and attitudes towards inclusion. Results of the study indicate that attitudes of regular preschool teachers towards inclusion are generally positive but mixed with concerns; regular preschool teachers' perceptions of school climate are positive which indicates favorable environmental conditions to implement inclusion; and more positive teachers' perceptions of school climate are associated with more positive teachers' attitudes towards inclusion. The Chinese government and education administration are encouraged to promote the creation of positive school climate as this correlational study suggests that school climate may affect teachers' attitudes. Implications and suggestions for future study are discussed.
\end{abstract}

Keywords-inclusion; preschool teachers; attitudes; perceptions of school climate

\section{INTRODUCTION}

Inclusion of students with special needs in general education has been drawing attention worldwide for years. Aimed at accommodating students of all levels, the concept of inclusive education was introduced and has now become one of the key strategies to ensure educational opportunity and equity, especially for students with special needs [1-4]. Major reforms and changes in education systems are in process internationally in both developed and developing countries. In 1994, the United Nations Educational, Scientific and Cultural Organization (UNESCO) proposed a "framework for action" to advocate inclusive education [5].

Sui Ban Jiu Du, literally translated as "Learning in Regular Classrooms" (LRC), is regarded by most Chinese scholars as a unique form of inclusion implemented in China [6-7]. Since the mid-1980s, China has initiated efforts and experiments on LRC. It is based on the concept and practice of inclusive education in Western countries, but is deeply rooted in the reality of special education in China. In China, it is generally agreed that "LRC is a form of special education for students with disabilities explored by China's special education professionals under the influence of Western mainstreaming in light of China's specific situation and it enables children with disabilities to enter ordinary schools in their vicinity and to undergo compulsory education in a fairly economical and rapid manner." [6] According to statistics published by the Ministry of Education of the People's Republic of China, there have been an increasing number of students with special needs entering regular classrooms. In 2010, the total number of students with special needs in school was 425,600 and among this about $65 \%$ stayed in regular schools [8].

Previous research shows that teacher attitude is a key factor predicting success in inclusion. However, few studies have been conducted empirically in China that focused on the importance of understanding teachers' attitudes towards inclusion. In addition, research on school climate revealed that school climate affects teachers' levels of confidence to promote learning, and teachers' perceptions of school climate is an indicator of success in inclusion [9-10]. However, little research in the past has focused on the direct relationship between teachers' perceptions of school climate and their attitudes towards inclusion. Therefore, the current study explores the direct relationship between teachers' perceptions of school climate and their attitudes towards inclusion in order to provide educators, administrators and policy makers with the perspectives of improving teachers' perceptions of school climate in promoting successful inclusive educational practices.

\section{LITERATURE REVIEW}

\section{A. Definition, Benefits, Concerns and Arguments of Inclusion}

Inclusion is defined by the United States National Center on Educational Restructuring and Inclusion as "providing to all students, including those with significant disabilities, equitable opportunities to receive effective educational services, with the needed supplementary aids and support services, in age appropriate classrooms in their neighborhood schools, in order to prepare students for productive lives as full members of society." [11] In response to Chinese policies and the status quo of inclusive implementations, Sui Ban Jiu Du (LRC) serves as the context in which the study is conducted.

The issue of full inclusion has brought about much discussion and debate under contemporary educational system worldwide. The least restrictive environment principle requires that students with special needs should have the opportunity to be educated with their typically developing peers to the 
greatest extent possible. "Inclusion is essential if education is to foster equality, equity, social and community integration, tolerance, diversity, and achievement for all students." [12] While studies show positive outcomes resulting from incorporating students with special needs into regular classrooms [13-14], concerns exist. Common concerns about inclusion among teachers include: competitive school culture, lack of resources and administrative supports, poor infrastructure, financial limitations, large class sizes, insufficient training, students' degrees of disabilities, and personal competences [15-17]. Among these concerns, competitive school culture, lack of resources and administrative supports, poor infrastructure, financial limitations, large class sizes etc. are within the range of teachers' perceptions of school climate in the implementation of inclusion.

"Early childhood education, assessment and if needed, intervention and documentation is imperative to ensure success.... If special needs exist (vision, speech, hearing, language) these areas must be documented." [18] Inclusion at the preschool level shows significant differences with that at the elementary and high school levels. The ingredients that make the process of inclusion unique at the preschool level include: "(1) the nature of preschool children's development and early childhood teaching practices, (2) organizational structures, and (3) teacher preparation." [19]

Inclusion of children with disabilities and the ensuring of their rights to have as full a life as possible is an ethical issue [20]. "Separating young children with handicaps [disabilities] from normal experiences creates distance, misunderstanding, and rejection...Moreover, separating these youngsters from the real world means that there must be reentry. Reentry problems can be avoided by not removing the child from normal settings." [21] In addition, from a developmental perspective, early years of life are crucial to later development and lay foundations for lifelong learning. Therefore, ensuring inclusion at the preschool level is of great importance.

\section{B. Teachers' Attitudes Towards Inclusion}

As more students with special needs are included in general education classrooms, attitudes of general education teachers towards inclusion become very important [22]. Teachers' values and attitudes play a central role in the success of inclusive programs [23] and attitudes towards disabilities and the perspectives from which disabilities are viewed can determine the quality of inclusion [24].

While most studies present positive teacher attitudes towards inclusion of students with special needs [25-26], some of the research reflected a sense of apprehensive and negative attitudes among pre-service teachers [16] [27] [28] [29]. Some recent studies concluded that the majority of teachers seem to hold undecided or negative attitudes towards inclusive education, and their attitudes are often based more on their practical concerns about how inclusive education can be implemented [30-31].

Demographic features were also found to be related to teachers' attitudes. Dukmak's study investigating teachers' attitudes towards inclusion in relation to their gender, age and years of teaching experience revealed that male teachers had more supportive attitudes towards inclusion than females; no statistically significant relevance was detected between teachers' age and their attitudes towards inclusion and years of working experiences was found to be a negative predictor of teachers' attitudes towards inclusion [32].

\section{School Climate and Teachers' Attitudes towards Inclusion}

Most researchers emphasized on the multidimensional nature of school climate as including physical, social and academic dimensions [33]. The current study echoes more with Zak's definition of organization climate as "the system of characteristics of the internal environment of the organization experienced by the participants as a group. It can be described in special characteristic terms and influences the behavior of the group members in direct and indirect ways." [34]

Previous research reported that positive school climate was found to be associated with higher job satisfaction, higher teacher commitment and better educational and psychological results for students and teachers [9] [10] [35]. Research studies on the relationship between school climate and inclusive education showed that principals' work and attitudes made a determinative contribution to the success of inclusion [36]. For schools where management did not support inclusion there tended to be a lack of cooperation among teachers and staff [37]. Teachers who perceived the school principal as supportive and encouraging were more open to innovation and ready to adjust teaching methods to benefit all students [38].

Since teachers' attitudes play a central role in inclusive practices and teachers' perceptions of school climate act as an important indicator of success in inclusion, the current study tries to examine the impact of teachers' perceptions of school climate on teachers' attitudes towards inclusion in order to provide educators, administrators and policy makers with a new perspective to push inclusion forward.

\section{METHODOLOGY}

\section{A. Research Questions}

Four research questions guide the whole study.1. What are the demographic characteristics of regular preschool teachers in Shanghai, China? 2. What are the attitudes of regular preschool teachers towards inclusion in Shanghai, China? 3. What perceptions of school climate are held by regular preschool teachers in Shanghai, China? 4. Are the perceptions of school climate of regular preschool teachers significantly associated with their attitudes towards inclusion, after controlling for demographic characteristics?

\section{B. Research Design and Sample Selection}

Aimed at investigating the relationship between teachers' attitudes towards inclusion and their perceptions of school climate, the current study adopts a non-experimental, quantitative, correlational research design. Target population of this study includes all the regular preschool teachers in public schools in Shanghai, China. Online questionnaire was administered and 816 respondents from four districts in Shanghai sent back their data. 


\section{Instrumentation}

Two scales were adopted in this study for data collection and analysis. First, the Attitudes towards Teaching All Students (ATTAS-mm) was utilized to measure teacher attitudes towards inclusion. The Cronbach's alpha of the full scale is 0.863 indicating good reliability of the scale. Second, the Revised School Climate Teacher Survey (SCTS-R) was used to measure teachers' perceptions of school climate. The Cronbach's alpha of the scale is 0.944 . The two scales were modified to ensure adequacy for the current study.

In addition, a survey was developed to gather teachers' demographic characteristics including gender, age, education level, years of teaching, knowing a person with disabilities, experience in teaching students with disabilities and special education training experiences.

\section{RESULTS AND DISCUSSIONS}

\section{A. Research Question 1: Preschool Teachers' Demographic Characteristics}

Demographic characteristics of preschool school teachers show that over $99 \%$ are females and nearly half are under 30 years old. Over 92\% hold a Bachelor's Degree or above and about $98 \%$ have very little or no experience in teaching students with special needs. More than $98 \%$ reported very little or no training in special education. And, one-third reported knowing a person with a disability.

Results reported from the current study reflect the previous research [39-40]. The only difference is in that participants involved are assigned to teach in primary and secondary versus preschool levels. Based on the fact that few empirical research studies have been carried out in China exploring early childhood inclusive education, statistics revealed from regular preschool teachers' demographic characteristics in Shanghai in the current study are not all encouraging. Three features can be inferred from the results for this research question. First, preschool teachers are almost all female; second, regular preschool teachers are receiving inadequate training of special education knowledge in both pre-service and in-service periods third, regular preschool teachers in Shanghai are young and well educated.

\section{B. Research Question 2: Preschool Teachers' Attitudes towards Inclusion}

To address preschool teachers' attitudes towards inclusion, a composite variable (AATTAS-mm) was made, by averaging across the nine items, to reflect respondents' (negative) attitudes, overall, towards inclusion. The lower the score, the more positive attitudes respondents hold towards inclusion. A mean score of 2.5285 indicates that regular preschool teachers enrolled in the study exhibited a somewhat positive attitude towards inclusion, on average. Less than $6 \%$ of the teachers' averages were in the "disagree" or "strongly disagree" range of $3.5-5.0$. Nearly half $(49 \%)$ were in the "strongly agree" or "agree" range of $1.0-2.5$. However, $45 \%$ of the teachers' averages across the nine attitude items fell in the "neutral" range of $2.5-3.5$.

The "neutral" attitude towards inclusion held by $45 \%$ of the participants appears to be reasonable given the previous research[15] [16] [17] [30] [31]. However, the supportive attitudes held by $49 \%$ of regular preschool teachers might change in the negative direction if they were asked to accept students with disabilities into their own classrooms because, in China, teachers have been found to have two seemingly contradictory feelings with inclusion [41]. They exhibit a high rate of support for inclusive education while they simultaneously express support for special (segregated) schools [42].

\section{Research Question 3: Preschool Teachers' Perceptions of School Climate}

To address preschool teachers' perceptions of school climate, ASCTS was made as the composite variable, by averaging 25 items, to reflect teachers' perceptions of school climate, overall. In this construct, higher scores on the scale mean that respondents hold more positive perceptions of their schools' climates. Hence, a mean score of 4.2686 indicates that teachers in regular preschools are positive in their perceptions of school climate, on average. In fact, none of the teachers' averages across the 25 school climate items were in the "disagree" or "strongly disagree" range of $1-2.5$. Less than $7 \%$ fell in the "neutral" range of $2.5-3.5$. Over half $(56 \%)$ were in the "agree" range $(3.5-4.5)$ and over one-third (37\%) were in the "strongly agree" range of $4.5-5.0$.

Scores on teachers' perceptions of school climate were high, and the self-report nature of the data may partially explain the results. The results showed that regular preschool teachers in Shanghai are very positive in their perceptions of school climate.Instead of the scores of sub-scales, the current study employed the total score of the scale to get an overall evaluation of preschool teachers' perceptions of school climate. In addition, as an instrument revised in 2014, no published article in China was yet found using this scale. Thus, this study's findings may aid future researchers by providing a point of comparison.

\section{Research Question 4: Relationship between Teachers' \\ Perceptions of School Climate and Their Attitudes towards Inclusion}

To examine the relationship between teachers' perceptions of school climate and their attitudes towards inclusion, regular preschool teachers' attitudes towards inclusion were regressed on their perceptions of school climate, after controlling for teachers' years of teaching experiences and special education training experiences, two demographic characteristics found to be significantly associated with teachers' attitudes towards inclusion and their perceptions of school climate.

The multiple regression was statistically significant $(\mathrm{R} 2=0.141, \mathrm{~F}[3,812]=44.315, \mathrm{p}<0.001)$. Initially, the two control variables together accounted for $3.1 \%$ of the variance in teachers' attitudes towards inclusion, $\mathrm{F}[2,813]=12.940$, $\mathrm{p}<0.001$. Teachers' perceptions of school climate explained an additional $11 \%$ of the variance in teachers' attitudes towards inclusion, $F[1,812]=103.791, p<0.001$. For each standard deviation increase in teachers' perceptions of school climate, there is an improvement of 0.335 standard deviations in their attitudes towards inclusion, while controlling for years of teaching and special education training experiences $(\beta=-0.335$, 
$\mathrm{p}<0.001)$. Higher scores on the outcome represented the opposite, which means the higher the score, the more negative teachers' attitudes are towards inclusion. Therefore, the regression coefficient associated with teachers' perceptions of school climate was expected to be negative. These results suggest that the more positive teachers' perceptions of school climate, the more supportive of inclusion their attitudes are, after controlling for years of teaching experience and special education training experiences.

TABLE I MultiPle Regression OF TEACHERS’ AtTITUdes TOWARDS INCLUSION ON THEIR PERCEPTIONS OF SCHOOL CLIMATE, AFTER CONTROLLING TEACHING AND SPECIAL EDUCATION TRAINING EXPERIENCES FOR YEARS $(\mathrm{N}=816)$

\begin{tabular}{|c|c|c|c|c|}
\hline Predictor & $b$ & $S E_{b}$ & $\beta$ & $t$ \\
\hline (constant) & 4.392 & 0.203 & & $21.615^{* *}$ \\
\hline Years of Teaching Exp. & 0.067 & 0.019 & 0.114 & $3.450^{* * *}$ \\
\hline Special Ed. Training Exp. & -0.077 & 0.045 & -0.056 & -1.712 \\
\hline Perceptions of School Climate re: Inclusion ${ }^{a}$ & -0.448 & 0.044 & -0.335 & $-10.188^{* *}$ \\
\hline
\end{tabular}

Since little research had focused on the direct relationship between school climate and teachers' attitudes towards inclusion, this study provides some preliminary empirical evidence on the claim that teachers' perceptions of school climate may exert positive influences on their attitudes towards inclusion. Therefore, preschools can improve inclusive levels by building positive school climate to help enhance teachers' positive attitudes towards inclusion.

\section{IMPLICATIONS FOR REGULAR PRESCHOOL INCLUSIVE EDUCATION IN CHINA}

Implications for regular preschool inclusive education, based on the results of the current study, are presented below. First, results reported from the current research and previous research conducted in China all indicated that general education teachers are not receiving enough training to teach in LRC classrooms. Even teachers who work in LRC classrooms in primary and secondary schools reported insufficient training [40]. To meet the diversified needs of students in class, teachers should strive to provide the least restrictive environment for each student, especially for students with special needs. Pre-service training of special education theories will get teachers prepared for teaching in inclusive classrooms while in-service training can provide teachers with practical instructions. In-service teachers should get more hands-on experiences teaching students with special needs in LRC classrooms under the instruction of special education teachers and get help from these experienced mentors to reduce, if not alleviate, possible concerns.

Second, the significant relationship found between teachers' perceptions of school climate and their attitudes towards inclusion offers insight to the future development of inclusive education in preschools. Creating a positive school climate may help improve teachers' attitudes towards inclusion and thereby could benefit students with special needs. Creation of positive school climate can be achieved by enhancing principal's work and attitudes to support inclusion and by promoting cooperation and collaboration among teachers.

\section{CONCLUSION AND SUGGESTIONS FOR FURTHER STUDY}

While tremendous efforts have been made at the compulsory education level to increase the number of classrooms in regular schools for special needs children, such progression has been very slow for similar needs children at the preschool level. Early childhood inclusion remains more of a topic for theoretical discussions among scholars [43-44]. The study results provide strong evidence that positive relationship exists between teachers' perceptions of school climate and their attitudes towards inclusion. Although high scores on teachers' perceptions of school climate and their attitudes towards inclusion are reported, the large proportion of teachers' negative responses on special education training experiences caution educators, administrators and policy makers to re-examine the environment created currently in Chinese preschools and its readiness to provide students with special needs the least restrictive environment. In the future, more male teachers should be enrolled to explore the gender difference among teachers in the process of inclusion, and qualitative research method should be adopted to get a more comprehensive view. In addition, the possible moderation role of teachers' perceptions of school climate and the role of teachers' self-efficacy levels could also be further investigated.

\section{REFERENCES}

[1] J. Aldridge,"Special education: A service, not a sentence," Childhood Education, vol.84, pp.181-182, 2008.

[2] N.S. Blecker, and N.J. Boakes, "Creating a learning environment for all children:Are teachers able and willing?" International Journal of Inclusive Education, vol.14, pp.435-447, 2010.

[3] J.H. Lei, and M. Deng, "On several relations in the process of developing inclusive education," Chinese Education and Society, vol.40, pp.33-43, 2007.

[4] L.N.K. Lo, "The sustainable development of inclusive education," Chinese Education and Society, vol. 40, pp.44-62, 2007.

[5] F.R. Guo, and Y.Z. Yi, "Report on the world special education Congress," Research on Special Education, vol.3, pp.1-4, 1994.

[6] M. Deng, and Z. Zhu, "The Chinese 'learning in a regular classroom' and Western inclusive education:A comparison and exploration," Chinese Education and Society, vol.40, pp.21-32, 2007.

[7] C.L. Liu, "Reflection on learning in regular class in China," Prospects, vol.38, pp154-160, 2008.

[8] X.G. Peng, "On the challenges facing China in the promotion of inclusive education and relevant suggestions," Chinese Journal of Special Education (Monthly), vol.11, pp.15-20, 2011. 
[9] W.K. Hoy, "Organizational climate and culture: A conceptual analyses of the school workplace," Journal of Educational and Psychological Consultation, vol.1, pp.149-168, 1990.

[10] D. L. Taylor, and A. Tashakkori, "Decision participation and school climate as predictors of job satisfaction and teachers' sense of efficacy," Journal of Experimental Education, vol.63, pp.217-231, 1995.

[11] City University of New York, NY. National Center on Educational Restructuring and Inclusion, p.5,1994.

[12] C. Savich, "Inclusion: The pros and cons-A critical review," ERIC, accession number: ED501775, 2008.

[13] A.H. Widerstrom, Achieving Learning Goals through Play: Teaching Young Children with Special Needs (2nd Ed.).Baltimore: Brookes Publishing Co., 2005.

[14] X.J. Yang, "On the feasibility for China to promote inclusive education," Chinese Journal of Special Education (Monthly), vol.11, pp.11-14, 2011 .

[15] N. Bhatnagar, and A. Das, "Regular school teachers' concerns and perceived barriers to implement inclusive education in New Delhi, India,' International Journal of Instruction, vol.7, pp.89-102, 2014.

[16] U. Sharma, and D. Moore, and S. Sonawane, "Attitudes and concerns of pre-service teachers regarding inclusion of students with disabilities into regular schools in Pune, India," Asia-Pacific Journal of Teacher Education, vol.37, pp.319-331, 2009.

[17] R.F. Snyder, "Inclusion: A qualitative study of in-service general education teachers' attitudes and concerns," Education, vol.120, pp.173-180, 1999.

[18] M.F. Shaughnessy, and K. Kleyn, Education in a Competitive and Globalizing World: Handbook of Early Childhood Education. Publisher: Nova, pp.6-7,2012.

[19] S.L. Odom,et al." Inclusion at the preschool level: An ecological systems analysis," Society for Research in Child Development, vol.10, pp.18-30, 1996.

[20] K.E. Allen, and G.E. Cowdery, The Exceptional Child: Inclusion in Early Childhood Education (5th Edition). Publisher: Thomson Delmar Learning, 2005.

[21] N.G. Haring, and L. McCormick, Exceptional children and youth. Columbus, OH: Merrill, p.102, 1990.

[22] J. Siegel, "Regular education teachers' attitudes towards their mainstreamed students," Paper presented at the annual Convention of the Council for Exceptional Children, Baltimore, MD, 1992.

[23] M.A. Winzer, "The inclusion movement and teacher change: Where are the limits?" McGill Journal of Education, vol.33, pp.229-251, 1998.

[24] J. Pivik, and J. McComas, and M. Laflamme, "Barriers and facilitators to inclusive education,"Exceptional Children, vol.69, pp.97-107, 2002.

[25] T.E.Scruggs, and M.A.Mastropieri,"Teacher perceptions of mainstreaming/inclusion, 1958-1995: Aresearch synthesis," Exceptional Children, vol.63, pp.59-74, 1996.

[26] Z.Shechtman, and S. Reiter, and M. Schanin, "Intrinsic motivation of teachers and the challenge of mainstreaming: an empirical investigation," Special Services in the Schools, vol.7, pp.107-124, 1993.

[27] W. King, and A. Edmunds, "Teachers' perceived needs to become more effective inclusion practitioners: A single school study," Exceptionality Education Canada, vol.11, pp.3-23, 2001.

[28] K.Parsuram, "Variables that affect teachers' attitudes towards disability and inclusive education in Mumbai, India," Disability and Society, vol.21, pp.231-242, 2006

[29] P. Stanovich, and A. Jordan, "Preparing general educators to teach in inclusive classrooms: Some food for thought," Teacher Educators, vol.37(3), pp.178-185, 2002.

[30] K. Burke, and C. Sutherland, "Attitudes towards inclusion: Knowledge vs. Experience,” Education, vol.125, pp163-172, 2004.

[31] T.E. Scruggs, "Teacher perceptions of mainstreaming/inclusion, 1958-1995: A research synthesis," Exceptional Children, vol.63, pp.59-74, 1996.

[32] S.J. Dukmak, "Regular classroom teachers' attitudes towards including students with disabilities in the regular classroom in the United Arab
Emirates,'The Journal of Human Resource and Adult Learning, vol.9, pp.26-39,2013.

[33] A. Loukas, "What is school climate?" Leadership Compass, vol.5, pp.1-3, 2007.

[34] I. Zak, Schools' organizational climate. In: A. Levi \& D. Nevo (Eds.) Evaluation Roles in Education. London: Gordon Breach, 1981.

[35] H.J. Freiberg, "Measuring the school climate: Let me count the ways," Educational Leadership, vol.56, pp.22-26, 1998.

[36] D. Mayrowetz, and C.S. Weinstein, "Sources of leadership for inclusive education: Creating schools for all children," Educational Administration Quarterly, vol.35, pp.423-449, 1999.

[37] N. Mamlin, "Despite best intentions: When inclusion fails," Journal of Special Education, vol.33, pp. 36-49, 1999.

[38] M. Fritz, and M. Miller, "Teacher perceptions: Impacts of planning for inclusion," Paper presented at the annual international convention of the council for exceptional students, Indianapolis, April, 1995.

[39] O. P. Malinen, and H. Savolainen, and J.C. Xu, "Beijing in-service teachers' self-efficacy and attitudes towards inclusive education," Teaching and Teacher Education, vol.28, pp.526-534, 2012.

[40] M. Wang, et al., "A survey study of Chinese in-service teachers' self-efficacy about inclusive education," Journal of International Special Needs Education, vol.15, pp.107-119, 2012

[41] G. Chen, and Y. Zhang, and Y. Shi, and L. Wang, and Y. Wu, "A review of research on teachers' attitudes towards learning in regular classrooms in mainland China," Chinese Journal of Special Education, vol.12, pp.27-32, 2006.

[42] M. Deng, "An urban-rural comparative study of the attitudes of ordinary elementary school LRC teachers towards inclusive education," Educational Research and Experiments, vol.1, pp.61-67, 2004.

[43] Z.Q. Wang, and R.H. Shen, "The challenge and discussion of including children with disabilities in regular classrooms-A case study," Journal of Chongqing Normal University Edition of Social Science, vol.2, pp.141-147, 2009

[44] B.Y. Hu, and J. Szente, "An introduction to Chinese early childhood inclusion," Springer Science + Business Media B.V., 2010 